\title{
Health Surveillance: An Operational Imperative?
}

\author{
Lt Col A Hawley \\ OBE,MB,ChB,DMCC,DOcc Med,RAMC
}

\section{Royal Defence Medical College, Horton Block, Gosport, Hants POI2 $2 A B$}

SUMMARY: Many recent operations have highlighted the problem of hazard exposure in troops. This is a difficult $\stackrel{\overrightarrow{\bar{N}}}{\stackrel{\overrightarrow{7}}{ }}$ area since it depends upon both post-deployment and possibly mid-deployment health surveillance and crosses the $\bar{C}$ traditional limits of occupation and public health medicine. Health surveillance is itself a term which straddles $\underline{\bar{E}}$ occupational and public health medicine. For the military population at risk on operations, a combined approach is $\frac{\omega}{\square}$ required incorporating the separate activities of needs and risk assessments. There is an existing vehicle to develop $\triangle$ this approach using the new $\mathrm{J95}$ methodology. Equally, a system of data access crossing medical and personnel records is necessary. The important requirement is that health surveillance is included in pre-deployment planning. $\vec{\circ}$ Only by this method can adequate resources and significance be accorded to appropriate health surveillance strategies both during and following an operation as required.

\section{Introduction}

Changing times need new attitudes and thinking. This is certainly true of the recent changes in military postures and deployments. Within the space of a single decade the whole edifice of NATO and Warsaw Pact confrontation has disappeared along with all certainties and predictability of that relationship (1). Also disappearing into history has been the deterrent based defence strategy enshrined in NATO's flexible response (2). The new doctrine of manoeuvre warfare and the manoeuvrist approach is a warfighting posture which derives its deterrent effect from a demonstrated ability to fight and win rather than the assured destruction inherent in NATO's previous strategy (3).

All this has important implications for military medicine. The delivery of effective and timely medical support becomes a crucial element of the operational plan. Since own casualties in the manoeuvrist approach are intended to be kept to a minimum, political acceptability of military action is maintained by correct care of those casualties incurred. In a very real sense, casualty figures have become politically sensitive. This issue has been demonstrated in recent deployments and in part reflects a changed set of expectations on behalf of public, soldiers and politicians (4). In brief, expectations are higher and margins for error are smaller. Acting as watchdog over this issue are the media whose duty is to report any shortfall in performance (5).

Driving this expectation spiral are the changes in society at large. In particular, the whole body of legislation embodied in the Health and Safety at Work Act (HSAW) as well as the Control of Substances Hazardous to Health (COSHH) simultaneously recognises and propels an obligation on behalf of employers and employees. This development represents a recent manifestation of a trend in regulating the effects of work on health (6). In terms of the uniformed services it presents a real challenge in accommodating the demands of operations to the spirit and letter of the law. Failure to meet the challenge will inevitably lead to public embarrassment and legal action with all the consequent adverse effects on Service morale and image.

The present difficulties over service in the Gulf War and $\stackrel{\vec{A}}{ }$ possible health effects sustained serve to illustrate this point. The concern over possible Gulf War associated $N$ illness has shown that casualties retain a political $\mathcal{E}^{\circ}$ significance both during and after operational events. Similarly, operational experience in the former Republic Yugoslavia has highlighted the difference in standards industrial hygiene between the West and the rest of the world. Other deployments are likely to involve service $\mathrm{f}$ areas of industrial pollution. These hazards may range from chemical to radiation dangers. Whatever their naturg, 9 the hazards will have to be recognised and a ris. management strategy developed for the operatio. Fortunately, a tool exists which may be adapted fö application in these circumstances.

\section{Risk Assessment and Management}

The method of risk assessment developed to meet the $\frac{\text { 의 }}{3}$ requirements of COSHH legislation (7) is of relevance and applicability to operational medical support. Integral and crucial to this approach is health surveillance. However, the methodology can be split down into various component parts all of which connect together seamlessly. Figure 1 explains the process schematically.

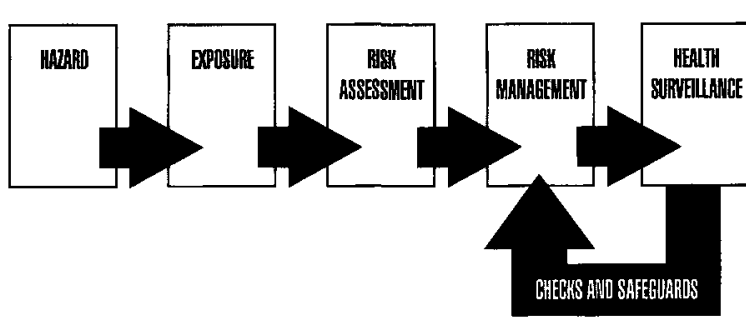

Fig 1. Risk Assessment and Management Process

Hazard identification is the initial step. At this stage some understanding of hazards faced by an individual is 
central to all that follows. For the sake of clarity, a hazard is defined as a substance or agent which possesses the potential of producing harm. From this definition it can be seen that hazards may be physical, chemical, biological or psychological. In a military setting it becomes crucial at this stage that adequate medical intelligence is available. Without it, hazard identification is difficult and will tend to incompleteness.

Having established the potential for harm, the next requirement is for the population at risk to be defined. It may be that all the deployed force will be exposed to a hazard. More frequently, there will be elements of the force which will be particularly and even specifically exposed. There may also be a fleeting exposure which all or some of the force may experience. At any rate some delineation of the exposed population must be made so that the next stage of risk assessment can be completed.

Having some measure of both hazard and exposed population, an estimate of the degree of risk is now possible. Just as a hazard hinges on the potential to cause harm, a risk depends upon the probability of harm being produced. Inevitably, judgement has to be exercised in arriving at the assessment; it is not an exact science, rather a common sense approach to an estimate process. However, it is a portentous step since flowing from the risk assessment will be a strategy for risk management. It is also medico-legally significant, since the recognition of a risk implies an undertaking to manage it. Failure to do so would be difficult to defend at law as well as ethically.

A successful risk management plan will seek to remove the hazard or failing that to control it. Controlling the exposure may be achieved by an engineering or procedural approach. If all else fails, the use of personal protective equipment will have to be considered. The intention of a risk management strategy is either to remove the possibility of harm to individuals or at least to reduce it to acceptable levels. In the parlance of COSHH, the aim must be to institute a safe operating and working system.

However, acting as a check and audit of the risk management plan will be health surveillance. The process may be conveniently split into three possible approaches; biological monitoring, biological effect monitoring and medical surveillance. Biological monitoring checks the presence of agents or their metabolites in the individual's body mass. An example of this is the use of alcohol analysis in breathalyser tests. On the other hand, biological effects monitoring is a system of checking the individual's response to an exposure; for instance, the altered liver enzymes consequent to prolonged alcohol ingestion. Finally, medical surveillance is the specific examination to establish the degree of damage or response which an individual has sustained. A relevant example of this is the periodic checking for tuberculosis amongst populations particularly at risk. Health surveillance in this context has a number of purposes including an audit of the risk management strategy as well as providing a basis for monitoring and treating individuals who have been affected by a particular exposure.

\section{The Interpretation of Health Surveillance}

One of the problems which bedevils any consideration of the health surveillance question is the meaning of the $\vec{z}$ term. The interpretation outlined above is that routinely $\varnothing$ understood and used in occupational medicine. It is a 8 focused surveillance in response to a defined hazard. The more general understanding is that used in public health as part of a needs assessment rather than a risk assessment. In $\overrightarrow{\vec{N}}$ this population based approach, various parameters are $\overrightarrow{0}$ measured as part of a process of trend identification. From this information, priorities can be set and resource decisions made. The needs assessment is crucial to $\widetilde{\alpha}$ sensitive management and resourcing of a health care system. Health surveillance is central to the process. However, it is not the same entity as that enshrined in risk management.

Much of the published work on health surveillance is concerned with general surveillance. Even some of the early studies on Gulf War illness followed this approach. Thus, Gray et al reviewed the post war hospitalisation experience of United States veterans of the Gulf War as compared with a similar group of military who did not serve in the Gulf (8). The study covered the period 25 months after the war and concluded that there was noc increased risk of unexplained hospitalisation during this $\mathrm{S}$ period for those who continued to serve after the wa. Similarly, Woodruff and Conway outlined a Heal Promotion Tracking System for health surveillance in the United States Navy $(9,10)$. They examined a system health surveillance which was a development of ân existing medical review programme. The intention was produce a systematic approach to surveillance which gate useful and accessible data on desired parameters. Amongs these data were the usual medical measurements of blood pressure, pulse rate and weight. Both of these studies could be classed as public health oriented surveillance programmes. They both fit admirably into the tradition of $\overrightarrow{\bar{a}}$ public health medicine and conform to the standard 3 methodologies reviewed by Declich and Carter (11). They clearly showed that health surveillance in a needs assessment setting is a driver of priorities and policies. Fundamentally, they are population based strategies.

In contrast, the psychological follow up to Operation ORDERLY (the ambulance duties carried out by the military during the strike of 1989) is an example of an occupational approach. Gillham and Abraham identified a hazard, psychological stress, and then examined the effect which it had caused on the exposed population (12). Such an approach conforms to the risk assessment/management model outlined above. However, it did require that a specific hazard was identified so that the resultant postexposure health surveillance was specific. Health surveillance is not a driver in this case but a check on risk management measures.

A more useful and pragmatic approach to health $N$ surveillance in military populations was discussed by Miller and Jefferson (13). Their definition has obvious utility - "health surveillance can be defined as the 
systematic observation of health problems with a view to preventing or treating disease." They also correctly pointed out that reliable data are the crucial components of a process of surveillance and that the recent introduction of the NATO wide reporting system is a major advance in this direction. Using the Miller/Jefferson definition, the separate requirements and purposes of risk and needs assessments can be resolved. As far as the military are concerned both activities are essential to both peacetime and operational medical planning. They are crucial tools in the primary function of a military medical service; the management of occupational risk. In addition the new reporting system, based on the J95 system pioneered by Jefferson (14), possesses the sensitivity and capability to be adapted to both a general trend identification as well as a specific post-exposure surveillance. All it needs is for a hazard to be identified so that search criteria can be inserted into the reporting system.

This is a real difficulty since the occupational model depends upon an identifiable and known hazard for its maximal utility. In the case of the Gulf War, it may be that a range of new and novel hazards were faced by servicemen. In such a case it is difficult to plan a specific health surveillance programme at the commencement of a deployment. Inevitably, there will be a need for a retrospective and more general approach to such situations. As the knowledge base on hazards expands, so more specific and sensitive health surveillance along the occupational model can be developed and adopted. Regular modification and updating of a database will allow the tailoring of a public health surveillance model to the specifics of a particular deployment. By this approach, the health planning and audit requirements of the military on operations can be accommodated.

Fortunately, the existing system of regular medical examinations can be used as a vehicle for general and specific post-deployment surveillance. The inclusion of medical surveillance on the occupational model is administratively possible. However, it does require means of both storing the necessary information and then gaining access to it. Data are only of value if they can be usefully employed. Clearly, some sort of link between medical surveillance data and personnel records has to be established in the event of a post-exposure follow-up. This issue is fraught with problems of confidentiality and information handling. However without it, a systematic post-operational medical surveillance programme is likely to be less effective than it might otherwise be.

Integral to this programme is the appropriate sampling strategy. One of the determinants of the sampling methodology will be the perception of the risk. Should the risk assessment suggest a high level of unavoidable exposure, it would be appropriate for a larger proportion of the exposed population to undergo health surveillance than in the case of a lesser assessment of risk. However, in addition to this population, there would still be the continuing need to provide health surveillance in some degree to individuals who showed some evidence of post- exposure change. Clearly, at the outset of a deployment it $\supset$ may not be possible to identify or more likely to quantify the risks adequately. This is particularly so in short notice operational deployments to developing countries and areas (15). In these circumstances, a review of the risks should be undertaken during the deployment so that appropriate health surveillance based on a meaningful sampling $c$ strategy can be implemented. It must be remembered that circumstances are dynamic and so the review of hazards $\stackrel{\vec{S}}{\rightarrow}$ and the risk assessment must be continuous.

The initiation of the health surveillance may actually occur whilst the operational deployment is still in place. If the assessment is such that the risk is deemed to be high, $\stackrel{\mathbb{D}}{\AA}$ then the initial stages of the health surveillance may be started in the operational zone. Naturally, one of the determinants of this will be the duration of the operation as well as the scale of the risk. Equally, it must be understood that the programme introduced on operations will not usually have the advantages of a United Kingdom based system. There will not normally be the same provision of laboratory and investigative support available. This will $\stackrel{\perp}{\vec{A}}$ have to be recognised when the decision to institute a health surveillance programme is taken. Still, although it $\mathrm{N}$ remains far from ideal, it remains a viable option and is recognition of the need for flexibility when dealing with dynamic requirements.

\section{Conclusions}

Military health surveillance should be viewed as $\mathbb{\Phi}$ crucial and integral component of the overall medic $\overrightarrow{0} \overrightarrow{0}$ estimate. It should form an important part of the medical $\infty$ and operational planning and should be resourced at the outset. Without this sort of provision, it is unlikely thig. adequate time, finance or material will be available for comprehensive surveillance programme. Equally, it must be accepted that health surveillance is critical to any deployment and must be included as a requirement by the operational staffs. This means that adequate medical intelligence and information is a prerequisite. Allied to this is the crucial importance of early involvement of preventive medical staffs.

Correct use of preventive medical staff extends beyond the intelligence stage. Experience in the Former Republic of Yugoslavia has confirmed the necessity of including specialist staff on reconnaissance tasks, particularly where accommodation and working conditions are concerned. Failure to meet this requirement greatly increases the chance of inadequate risk assessments being undertaken with all the consequent problems for possible avoidable o exposures to hazards. Necessarily, this will complicate the whole problem of post-deployment health surveillance. As 윽 with many aspects of military, there is a seamless thread which runs through the cycle of intelligencereconnaissance-risk assessment-risk management-health surveillance. Compromise on one will affect all. At Figure 2 is a representation of the relationship between risk $N$ assessment/risk management and operational planning. The bold lines indicate strong links whilst the dotted lines 0 


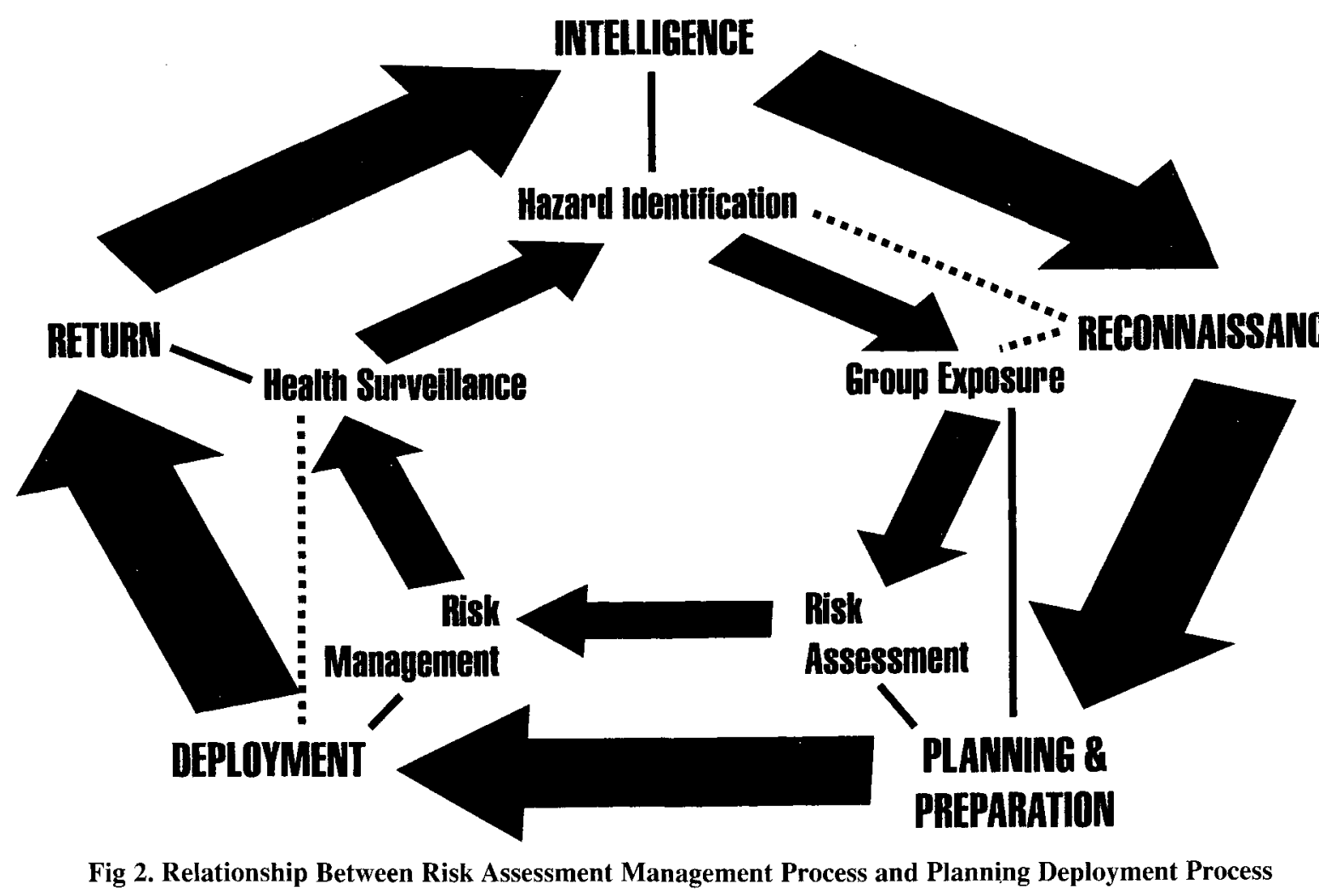

show confirmatory or possible links.

The logic of military health surveillance is clear. Its philosophy is simple and easily understood. The problems lie with the implementation. A system of data transfer between personnel records (with details of operational tours and possible exposures to hazards) and medical records (holding all details of medical examinations and investigations) needs to be instituted. This link will enable access to information by those who need it and are authorised to receive it. There must always be a concern for the maintenance of confidentiality and this concern involves sensitive material held by both medical and personnel staff.

Equally, there has to be a clear policy of health surveillance laid down as part of an operational instruction. This must be capable of being fulfilled by the medical staff and so requires the protocols to be kept simple and robust. Incomprehension or lack of resources at medical centre level will render any health surveillance meaningless. Unfortunately, although information transfer may be facilitated, the process of communication may not be enhanced. It will require the full assistance of the medical chain of command to institute a successful health surveillance process.

Despite the difficulties inherent in setting up a system of post-exposure health surveillance, it is clear that there will be a continuing need for such a system. Without it, the medical services will be condemned to an existence of endless hypothesis and conjecture when faced by urgento enquiries from operational staffs about service personne health during and following operational deployments. Tfee system should be based on a general health surveillanofos infrastructure adapted to the risk assessment. It requires and integrated approach to preventive medicine rather than a narrow professional purview. The tools for such an approach exist. All it requires is that we use them.

\section{REFERENCES}

1. FREEDMAN L. Security and the Diffusion of Power. In: Brassey's Defence Yearbook 1997. London: Brassey's, 1997; 7-19.

2. Hunt K. Alternative Conventional Force Postures. in NATO The Next Thirty Years. London: Croom Helm, $1980 ; 133-148$.

3. Thomas INA. Manoeuvre Warfare - Its Place in Britisho Military Doctrine. British Army Review 1995; 100: 75 83.

4. DIEHL PF. International Peacekeeping. Baltimore: Johns Hopkins, 1994: 184-190.

5. LloYd C. The Case for the Media. In: Defence and the Media in Time of Limited War. Young PR, Ed. London, 1992: 44-68.

6. Carter JT. The Role of Government in Preventing Illo Health at Work. In: Hunter's Diseases of Occupations. London: Edward Arnold, 1994: 15-20.

7. CoshH 1994: Approved Codes of Practice. HSE 
Sudbury, 1994.

8. Gray CG, Coate BD, Anderson CM, et al. The Postwar Hospitalization Experience of U.S. Veterans of the Persian Gulf War. $N$ Engl J Med 1996; 335: 1505-1513.

9. WoOdRUFF SI, ConwaY TL. U.S. Navy Health Surveillance, Part 1: Feasibility of a Health Promotion Tracking System. Milit Med 1994: 159: 24-31.

10. WoodrufF SI, ConwaY TL. U.S. Navy Health Surveillance, Part 2: Responses to a Health Promotion Tracking Survey. Milit Med 1994: 159: 32-37.

11. DeClich S, CARTER AO. Public Health Surveillance: Historical Origins, Methods and Evaluation. WHO Bulletin OMS 1994: 72: 285-304.
12. Gillham AB, Abraham P. Operation Orderly Prevalence and Degree of Distress Among Military Personnel Following Their Ambulance Experiences in London District. J R Army Med Corps 1992; 138: 23 26.

13. Miller SAStJ, JefFerson TO. Military Health Surveillance. Editorial in J R Army Med Corps 1997; 143: 3.

14. JeFFERSON TO. Pilot Study of the Introduction of the J95 Health Data Collection System. J R Army Med Corps 1996; 142: 25-29.

15. HAwLEY A. Rwanda 1994: A Study of Medical Support in Military Humanitarian Operations. $J R$ Army Med Corps 1997; 143: 75-82. 